\title{
An Analytical Framework for Rapid Estimate of Rain Rate
}

\section{during Tropical Cyclones}

\author{
Reda Snaiki, Teng $\mathrm{Wu}^{*}$ \\ Department of Civil, Structural and Environmental Engineering, University at Buffalo, State \\ University of New York, Buffalo, NY 14126, USA \\ *Corresponding author. Email: tengwu@buffalo.edu
}

Abstract: An analytical framework for rapid estimate of rain rate during a translating tropical cyclone was proposed in this study. The efficient analysis framework for rain field is based on the observation that rain-induced momentum flux at Earth's surface cannot be ignored. The total surface stress results mainly from momentum flux contributions of wind and rain. A heightresolving wind field was utilized during the model construction leading to a linear, analytical solution of the surface rain rate. The obtained rain rate model explicitly depends on parameters for a typical tropical cyclone wind field simulation, namely storm location, approach angle, translation speed, radius of maximum wind, pressure profile, surface drag coefficient, and turbulent diffusivity. Hence, it could be readily implemented into state-of-the-art tropical cyclone risk assessment using the Monte Carlo technique. The rainbands in the proposed methodology were simulated using a local perturbation scheme. Sensitivity analysis of the rainfall field to the abovementioned parameters was comprehensively conducted. The results generated by the present analytical framework for rapid estimate of rain rate during tropical cyclones are consistent with field measurements.

Keywords: Tropical cyclone, rain rate, wind field simulation, rain-induced stress. 


\section{Introduction}

24 Tropical cyclones are responsible for the substantial part of natural hazard-induced economic and

25 life losses through high winds, torrential rain and wind-driven storm surge. Among these, the 26 rainfall-induced inland flooding contributes to a significant portion of the tropical cyclone related

27 damages (e.g., Landsea 2000; Rappaport 2000). Therefore, the rain field simulation inside the 28 tropical cyclone has attracted interest of a number of researchers for a better rainfall hazard 29 assessment. While there have been considerable advances in improving the simulation accuracy 30 of tropical cyclone rain field based on high-fidelity numerical weather prediction models, they are 31 not practical for risk assessment due to their high computational demands. Usually, the rainfall 32 distribution can be efficiently characterized based on probabilistic, parametric or physically-based 33 schemes.

The probabilistic models give good insights on the exceedance rate of specific rainfall intensities, and are often used to predict the extreme rain rates. The development of this type of models usually suffer from a lack of a large number of historical data that are needed to fit the

37 selected distributions. In addition, they are generally unable to represent the most important physics governing the rain field inside the tropical cyclone (e.g., sea surface temperature, moisture 39 distribution, vertical wind shear, hurricane intensity and translational velocity). Actually, no 40 physical justification has been provided for the use of the popular distributions such as lognormal, 41 mixed-exponential and Gamma curves to fit the data (e.g., Woolhiser and Roldan 1982; Groisman 42 et al. 1999; Wilson and Toumi 2005). 
2010), a joint satellite mission of the National Aeronautics and Space Administration (NASA) and

46 the Japan Aerospace Exploration Agency (JAXA), has released a significant amount of tropical

47 cyclone rainfall data. The goal of TRMM is to provide good estimates of global precipitation using

48 satellite observations. TRMM contains several instruments, namely the TRMM Microwave

49 Imager (TMI), the Precipitation Radar (PR), the Visible Infrared Scanner (VIRS), the Lightning

50 Imaging Sensor (LIS), and the Clouds and Earth's Radiant Energy System (CERES). Details of the

51 TRMM instruments are given in Kummerow et al. (1998). Several empirical models have been

52 developed based on the TRMM database. For example, Lonfat et al. (2004) acquired the spatial

53 distribution of the rain field over the ocean using the TMI data from 1998 to 2000. The rain rates

54 were found to be heavily dependent on the sustained surface wind speed. The rain rate achieved

55 the maximum value near the radius of maximum winds and then decayed exponentially. According

56 to the hurricane intensities grouped into three categories, i.e., tropical storms, category 1-2 tropical

57 cyclones, and category 3-5 tropical cyclones, different radial variations of the rain rate were

58 obtained. Based on the findings from Lonfat et al. (2004) together with the surface rain gauge data,

59 Tuleya et al. (2007) proposed the Rainfall Climatology and Persistence (R-CLIPER) model. In this

60 parametric model, the rain rate presented a Rankine-like profile with a linear variation from the

61 tropical cyclone center to the radius of maximum rain rate, followed by an exponential decay. In

62 addition, it has been proved using the findings of Kaplan and DeMaria (1995) that the hurricane

63 rain rates and wind speeds are always highly correlated before/after landfall. While the R-CLIPER

64 model could be employed over both the ocean and land, it assumed a symmetric distribution of the

65 rain rate inside the tropical cyclone. Lonfat et al. (2007) improved the spatial variation of the rain

66 field by introducing a modified version of the R-CLIPER model known as the Parametric

67 Hurricane Rainfall Model (PHRaM) with consideration of the wind shear effects. However, both 
the R-CLIPER and PHRaM models were found to underestimate the maximum rain rate since they

69 are based on the ensemble averages of numerous hurricanes (Tuleya et al. 2007).

Very few physics-based rain rate models have been introduced in the technical literature.

71 In the theoretical model proposed by Langousis and Veneziano (2009a), it is assumed that all the

72 upward moisture flux at the top of the tropical cyclone boundary layer is converted into rainfall.

73 The vertical moisture flux was evaluated from the vertical winds at a reference height, generated

74 by a modified version of the wind field model proposed by Smith (1968), along with the depth-

75 averaged temperature and saturation ratio. Although observations from Hurricane Frances

76 presented a maximum correlation (around 0.85) between the surface rain and vertical wind at an

77 elevation of 2-3 km, more comprehensive data may be necessary for the selected reference height.

78 Also, it is not easy to implement the modified version of Smith's non-linear model in the Monte

79 Carlo technique with a large number of simulations needed. While the model by Langousis and

80 Veneziano (2009a) has been demonstrated to provide good estimates of the tropical cyclone rain

81 rate, it cannot account for post landfall scenarios.

In this study, a new, analytical framework for tropical cyclones rain rate estimate will be developed for high-efficiency simulations. The rain rate analysis framework is based on the 84 observation that rain-induced momentum flux at Earth's surface cannot be ignored (e.g., Caldwell and Elliot 1971; 1972; Zhao et al. 2013). The total surface stress results mainly from momentum

86 flux contributions of wind and rain. A general formula of the rain intensity has been first derived 87 in which the iteration approach was utilized in the computation. The proposed methodology is able 88 to effectively integrate an efficient wind field model for rapid estimation of rain intensity during 89 tropical cyclones. Specifically, a height-resolving scheme recently developed by Snaiki and Wu 90 (2017a; 2017b) was utilized leading to a linear, analytical solution of the surface rain rate. The 
91 rainbands in the proposed methodology were simulated using a local perturbation scheme (e.g.,

92 Samsury and Zipser 1995; Holland et al. 2010; Li and Wang 2012). Sensitivity analysis of the

93 rainfall field to several essential parameters in the rain rate simulation was comprehensively

94 conducted. The present analytical framework for rapid rain rate estimation has been validated

95 using observation data obtained from various hurricanes.

\section{An analytical framework for rain rate estimation}

97 The heat and moisture fluxes that are considered as the fuel and the surface stress contributing to 98 the dissipation essentially govern the intensity of a tropical cyclone (Chen et al. 2007), as 99 illustrated in Fig. 1.

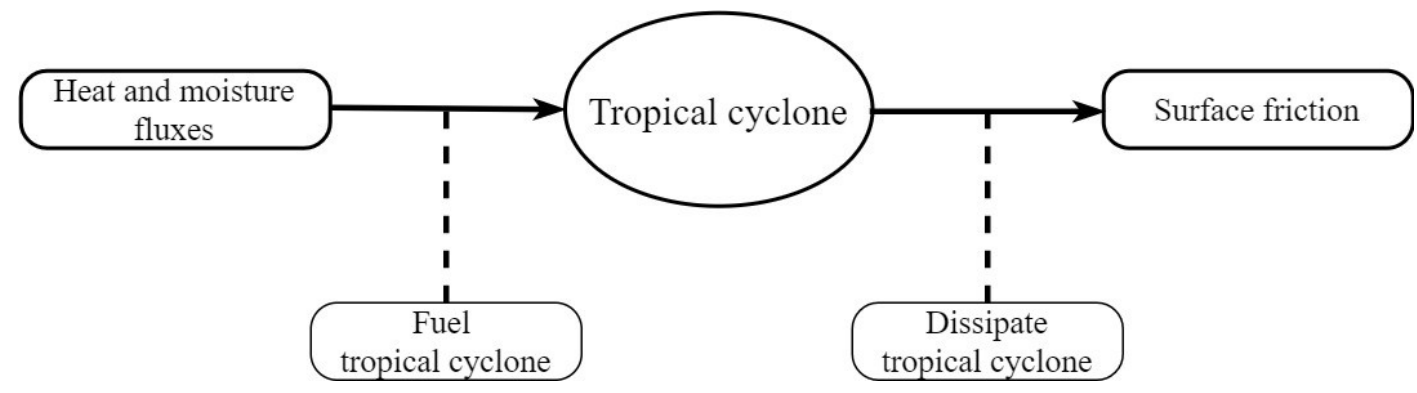

Fig. 1. Major processes governing tropical cyclone intensity

In this study, the modeling of rain intensity is based on the dissipation process of tropical cyclones where the total momentum flux is decomposed into several stress contributions. The general 105 practice to consider the total surface shear stress or equivalently the momentum flux density $\tau$ is 106 based on the following parameterization (Andreas 2004; Donelan et al. 2004; Jarosz et al. 2007;

107 Huang 2012):

$108 \tau \equiv \rho_{a} u_{*}^{2}$ effective 
109 where $u_{* \text { effective }}=$ effective frictional velocity during rain; and $\rho_{a}=$ air density. This

110 parameterization has been used in a number of applications such as the Fifth-generation

111 Pennsylvania State University-National Center for Atmospheric Research Mesoscale Model

112 (MM5) and the fully coupled atmosphere-wave-ocean model (AWO) (e.g., Chen et al. 2013).

113 Furthermore, the effective frictional velocity can be related to the effective drag coefficient

$114 C_{d, \text { effective }}$ and the wind speed $V_{\text {wind }}$ based on the following formula:

$115 \quad u_{*}^{2}$ effective $=C_{d, \text { effective }} V_{\text {wind }}^{2}$

116 Therefore, the total shear stress can be expressed as:

$117 \tau \equiv \rho_{a} C_{d, \text { effective }} V_{\text {wind }}^{2}$

118 The square law as indicated in Eq. (3) has been comprehensively validated, especially at high wind 119 speeds, with a number of observations (Garratt 1977).

Various factors may contribute to the total surface stress, namely the turbulent fluxes, rain 121 effects, spray, airborne sediment (Saltation theory) and convection-induced stress. It is assumed

122 here that no airborne sediment exists, therefore its momentum flux contribution is disregarded as

123 well as the convection-induced stress (Huang 2012). The spray actually does not add extra 124 momentum to the system but redistributes the wind stress near the surface (Andreas 2004). Since 125 the droplets around the spray evaporate quickly (Emanuel 1995), its contribution is typically 126 negligible (e.g., Wu 1973; Fairall et al. 1994). On the other hand, the rain-induced momentum flux

127 can be significant as the raindrops interact with the near-surface wind and transfer momentum to 128 the surface (Caldwell and Elliot 1971; 1972). Zhao et al. (2013) compared the rain-induced 129 horizontal stress and the wind stress at various wind speeds and rain rates. It was demonstrated 
130 that the horizontal stress by rain can have the same order of magnitude with that by wind.

131 Therefore, it is important to consider the rain-induced stress contribution to the total stress near

132 the surface. The total stress is then partitioned between two momentum contributions as:

$133 \tau=\tau_{a}+\tau_{r}$

134 where $\tau_{a}=$ momentum flux contribution from wind; and $\tau_{r}=$ momentum flux contribution from

135 rain. The wind stress $\tau_{a}$ can be expressed, in a similar way as in Eq. (3), in terms of the drag

136 coefficient $C_{d}$ without rain effects:

$137 \tau_{a} \equiv \rho_{a} C_{d} V_{\text {wind }}^{2}$

138 A widely used parametrization of the rain stress relates it to the rain rate and wind speed as

139 (Caldwell and Elliott 1971; 1972):

$140 \tau_{r} \equiv \gamma_{r} \rho_{r} V_{\text {wind }} R$

141 where $\rho_{r}=$ density of rainwater; $\gamma_{r}=$ empirically determined factor varying between 0.8 and 0.9 ;

142 and $R=$ rain rate. In this study $\gamma_{r}=0.85$ will be adopted (Caldwell and Elliott 1971; Wong and

143 Toumi 2016). The parameterization of Eq. (6) has been incorporated in several models, e.g., the

144 one-dimensional mixed-layer model developed by Clayson and Kantha (1999), the bulk

145 parametrization outlined by Fairall et al. (1996), and the Regional Ocean Modelling System

146 (ROMS). Equations (3), (4), (5) and (6) lead to the following formula of the rain rate:

$147 \quad R=\frac{\rho_{a} C_{d, \text { effective }} V_{\text {wind }}^{2}-\rho_{a} C_{d} V_{\text {wind }}^{2}}{\gamma_{r} \rho_{r} V_{\text {wind }}}$

148 It is interesting to note that the obtained rain rate formula implies that the rain-induced stress is

149 proportional to the wind-induced one. The wind stress is well known to be responsible to maintain 
150 the observed wind velocity profile in the atmospheric boundary layer (Taylor 1916). Since the

151 wind and rain horizontal velocities are proportional to each other (e.g., Guo et al. 2001; Fu et al.

152 2015), the relation between wind and rain-induced stresses indicated in Eq. (7) is reasonable. The

153 effective drag can be related to the roughness length based on the logarithmic law of wind profile

154 in the vicinity of the surface as (Meng et al. 1995; Bryant and Akbar 2016):

$155 \quad C_{d, \text { effective }}=\frac{\kappa^{2}}{\left[\ln \left(\frac{z_{10}}{z_{0, \text { effective }}}\right)\right]^{2}}$

156 where $\kappa=$ von Karman coefficient; $z_{0, \text { effective }}=$ the effective roughness length; and $z_{10}=10 \mathrm{~m}$.

157 Similarly, the drag coefficient $C_{d}$ (no rain effects) can be expressed in terms of the roughness

158 length $z_{0}$ as $C_{d}=\kappa^{2} /\left[\ln \left(\frac{z_{10}}{z_{0}}\right)\right]^{2}$.

The studies of characterizing the rain-induced roughness length over land are very limited.

160 On the other hand, the logarithmic profile well representing the lower part of the boundary-layer

161 winds over both the ocean and land as indicate by a large number of field measurements (e.g.,

162 Powell et al. 2003; Vickery et al. 2009; Tse et al. 2013, Shu et al. 2017) provides a good approach

163 for the estimation of the effective frictional velocity. As a result, the effective drag coefficient

$164 C_{d, \text { effective }}$ may be obtained through the least squares fit of the measured or simulated (considering

165 rain effects) vertical wind speed profile in the linear logarithmic space (e.g., Powell et al. 2003;

166 Holthuijsen et al. 2012; Vickery et al. 2009; Bell et al. 2012). In this study, the height-resolving,

167 wind-rain interaction model developed by Snaiki and Wu (2017c) (see Appendix A) is utilized.

168 Since the rain rate is a necessary input to take the rain effects into account, the iteration technique

169 is employed in the simulation as illustrated by Fig. 2. 


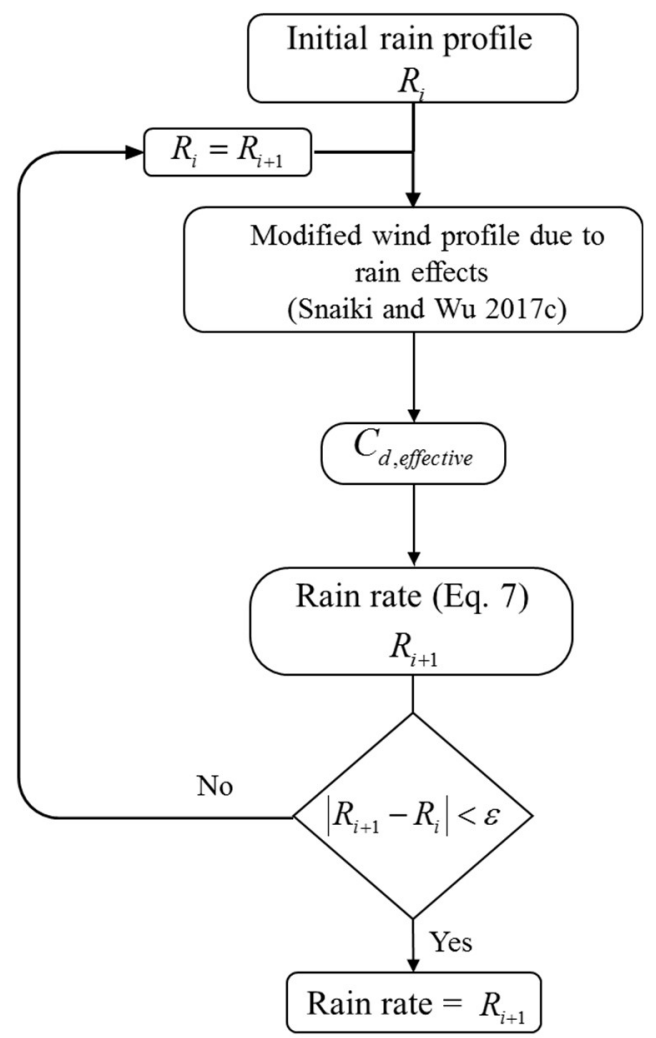

Fig. 2. Flow chart of the rain intensity simulation methodology

172

173 The initial guess of the rain profile could be based on an empirical model as follows (Snaiki and

$174 \mathrm{Wu} 2017 \mathrm{c})$ :

$175 R=R_{r m}\left\{\left(\frac{r_{m}}{r}\right)^{b} \exp \left[1-\left(\frac{r_{m}}{r}\right)^{b}\right]\right\}^{0.5}$

176 where $R_{r m}=$ maximum rain rate located at the radius of maximum wind $r_{m} ; r=$ radial distance

177 from the tropical cyclone center; and $b=$ scaling parameter that adjusts the profile shape and

178 depends on the radial extent of the tropical cyclone rain field. The maximum rain rate $R_{r m}$ was

179 estimated with an empirical formula available in literature (Tuleya et al. 2007):

180

$R_{r m}=a+b\left[1+\left(V_{m}-35\right) / 33\right]$ 
181 where $a$ and $b=$ constants from the least squares fit of the TRMM radial rainfall rates; and $V_{m}=$ 182 maximum wind speed. Although the iterative calculation is required in the analysis, it converges 183 quite rapidly. With a good initial guess of the rain profile based on Eq. (9), two or three iterations 184 are needed with a prescribed threshold $\varepsilon=5 \%$ for all simulations in the present study. The first185 order closure of the rain rate simulation in Fig. 2 results in a simplified model of Eq. (7):

$186 \quad R=\frac{\rho_{a} k_{m} \frac{d V_{\text {wind, } \text { modified }}}{d z}-\rho_{a} k_{m} \frac{d V_{\text {wind }}}{d z}}{\gamma_{r} \rho_{r} V_{\text {wind }}}$

187 where $k_{m}=100 \mathrm{~m}^{2} / \mathrm{s}$ is the eddy viscosity; $V_{\text {wind,modified }}=$ modified wind speed due to the rain effects.

189 expressed as a combination of the aerodynamic roughness length $z_{0}$ and the rain-induced one $z_{0, r}$

190 (Kumar et al. 2009):

$191 z_{0, \text { effective }}=z_{0}+z_{o, r}$

192 Several formulas have been proposed in the literature to characterize the rain-induced roughness

193 length $z_{0, r}$ over ocean. For instance, Kitaigorodskii [referred in Houk and Green (1976)] defined $194 z_{0, r}$ as:

$195 z_{o, r}=0.03 \sigma$

196 where $\sigma$ is the standard deviation of the experimentally obtained mean water level:

$197 \sigma=\beta \frac{k D}{g v}$ 
198 where $\beta=$ a constant of $0.01 ; D=$ drop diameter; $g=$ gravitational acceleration; $v=$ kinematic

199 viscosity of water; and $k$ is the rain kinetic energy flux that can be related to the rain intensity $R$ 200 and the terminal velocity of the rain drop $V_{t}$ :

$201 \quad k=\frac{R V_{t}^{2}}{2}$

202 As a result, the rain-induced roughness can be expressed as:

$203 z_{0, r}=\frac{0.015 \beta D V_{t}^{2} R}{g v}$

204 Accordingly, the rain rate over ocean can be calculated as:

205

$R=\frac{\rho_{a} \kappa^{2} V_{\text {wind }}\left(\left[\ln \left(\frac{z_{10}}{z_{0}+z_{0, r}}\right)\right]^{-2}-\left[\ln \left(\frac{z_{10}}{z_{0}}\right)\right]^{-2}\right)}{\gamma_{r} \rho_{r}}$

206 It should be noted that the use of Eq. (17) requires an iteration process since the rain-induced

207 roughness length $z_{0, r}$ depends on the rain intensity.

\section{3. Wind field model}

209 The proposed analytical framework for rapid estimate of the rain rate requires the horizontal wind

210 speed components as input. A recently developed height-resolving model by Snaiki and Wu

$211(2017 \mathrm{a} ; 2017 \mathrm{~b})$ is utilized here due to its high efficiency to obtain the wind field. A brief discussion

212 of the wind field model is presented in this section for the sake of completeness. The governing

213 equation of the wind field is described as follows: 
$214 \quad \frac{\partial \boldsymbol{v}}{\partial t}+\boldsymbol{v} \cdot \nabla \boldsymbol{v}=-\frac{1}{\rho_{a}} \nabla p-f \boldsymbol{k} \times \boldsymbol{v}+\boldsymbol{F}$

215 where $f=$ Coriolis parameter; $p=$ pressure; $\boldsymbol{k}=$ unit vector in the vertical direction; and $\boldsymbol{F}=$

216 frictional force. In order to solve Eq. (18), the decomposition method is used where the wind

217 velocity $(v)$ is expressed as:

$218 v=v_{g}+v^{\prime}$

219 where $\boldsymbol{v}_{\boldsymbol{g}}=$ gradient wind in the free atmosphere; and $\boldsymbol{v}^{\prime}=$ frictional component near the ground 220 surface. The solution of the gradient wind speed could be solved straightforwardly in the 221 cylindrical coordinate system (Georgiou 1986; Meng et al. 1995):

$222 v_{\theta g}=\frac{(-c \sin (\theta-v)-f r)}{2}+\left[\frac{(-c \sin (\theta-v)-f r)^{2}}{4}+\frac{r}{\rho_{a}} \frac{\partial p}{\partial r}\right]^{1 / 2}$

223 where $v=$ approach angle (counter clockwise positive from the East); $c=$ translation speed of the

224 tropical cyclone; and $\theta=$ azimuthal angle. The radial velocity $v_{r g}=-\frac{1}{r} \int_{0}^{r} \frac{\partial v_{\theta g}}{\partial \theta} d r$ obtained from the 225 continuity equation is usually disregarded due to its insignificant effects (Meng et al. 1995).

226 To obtain the frictional wind speed component, the nonlinear governing equation is first 227 simplified using the scale analysis approach, and then linearized leading to the following frictional 228 wind speed formulas as:

$229 u^{\prime}\left(\theta, z^{\prime}\right)=(\alpha / \beta)^{1 / 2} \times \operatorname{Real}\left\{A_{0} \times e^{\left(q_{0} z^{\prime}\right)}+A_{1} \times e^{\left(q_{1} z^{\prime}+i \theta\right)}+A_{-1} \times e^{\left(q_{-1} z^{\prime}-i \theta\right)}\right\}$

$v^{\prime}\left(\theta, z^{\prime}\right)=\operatorname{Imag}\left\{A_{0} \times e^{\left(q_{0} z^{\prime}\right)}+A_{1} \times e^{\left(q_{1} z^{\prime}+i \theta\right)}+A_{-1} \times e^{\left(q_{-1} z^{\prime}-i \theta\right)}\right\}$ 
231 where $\left(u^{\prime}, v^{\prime}\right)=$ frictional components of the wind velocity; $q_{1}=-(1+i)[\gamma+\sqrt{\alpha \beta}-\phi]^{1 / 2}$;

$232 q_{-1}=-(1+i)[-\gamma+\sqrt{\alpha \beta}-\phi]^{1 / 2} ; \quad q_{0}=-(\alpha \beta)^{1 / 4} ; \quad \alpha=\frac{1}{2 k_{m}} \xi_{g} ; \quad \beta=\frac{1}{2 k_{m}} \xi_{a g} ; \quad \xi_{g}=\frac{2 v_{\theta g}}{r}+f \quad$ is the

233 absolute angular velocity; $\xi_{a g}=\frac{\partial v_{\theta g}}{\partial r}+\frac{v_{\theta g}}{r}+f$ is the vertical component of absolute vorticity of the

234 gradient wind; $\gamma=\frac{1}{2 K} \frac{v_{\theta g}}{r} ; \phi=\frac{1}{2 K r} \frac{\partial v_{\theta g}}{\partial \theta}$; and $z^{\prime}=$ new vertical coordinate used as the base of the

235 computation scheme where $z^{\prime}=0$ is located above $z_{10}$ (i.e., the $10 \mathrm{~m}$ height above the mean height

236 of roughness elements) (Meng et al. 1995). The other necessary parameters needed for the

237 simulation can be acquired in Snaiki and $\mathrm{Wu}(2017 \mathrm{a} ; 2017 \mathrm{~b})$.

\section{4. Model validation}

239 The necessary parameters needed for the tropical cyclone wind field simulation are: $v$ approach 240 angle; $c$ translation velocity of the hurricane; $p_{c}$ central pressure; $\Delta p$ central pressure difference;

$241 R_{\max }$ radius of maximum winds; $B$ Holland's parameter; $\psi$ latitude; and $\lambda$ longitude. These wind

242 parameters can be obtained from the National Hurricane Center's North Atlantic Hurricane 243 Database (HURDAT). On the other hand, the tropical cyclone rainfall data can be acquired from 244 the high-fidelity numerical weather prediction models, the Tropical Rainfall Measuring Mission 245 (TRMM) database or the Radar observations.

\section{4.1. Comparison with MM5 model}

247 In this section, the ensemble average of 12 surface rain fields corresponding to hurricane Frances 248 (2004) in the period from $29^{\text {th }}$ August to $1^{\text {st }}$ September 2004 (6-h intervals) were simulated based 
249 on the Fifth-Generation Pennsylvania State University/NCAR Mesoscale Model (MM5)

250 (Langousis and Veneziano 2009a). A resolution of $1.67 \mathrm{~km}$ was used to generate the azimuthally

251 averaged rain rates in the MM5 simulations. The rain rates obtained from MM5 were compared

252 with those based on the proposed analytical framework, where the necessary parameters for the

253 rain intensity simulation were extracted from the HURDAT database (Table 1). As shown in Fig.3,

254 a good agreement between the MM5 and present simulation results is achieved.

255 Table 1. Tropical cyclones characteristics of the selected 12 rain fields

\begin{tabular}{cccccccc}
\hline & \multicolumn{2}{c}{ Hurricane Center } & & & & & \\
Mon|Day|h & $\begin{array}{c}\text { Latitude } \\
(\mathrm{deg})\end{array}$ & $\begin{array}{c}\text { Longitude } \\
(\mathrm{deg})\end{array}$ & $\begin{array}{c}\text { Storm Speed } \\
(\mathrm{m} / \mathrm{s})\end{array}$ & $\begin{array}{c}\text { Storm Direction } \\
(\mathrm{deg})\end{array}$ & $\begin{array}{c}V_{\max } \\
(\mathrm{m} / \mathrm{s})\end{array}$ & $\begin{array}{c}\Delta p \\
(\mathrm{hpa})\end{array}$ & $\begin{array}{c}R_{\max } \\
(\mathrm{km})\end{array}$ \\
\hline $08|29| 00$ & 18.1 & -52.9 & 4.0 & 145 & 59.2 & 948 & 31 \\
$08|29| 06$ & 18.4 & -53.6 & 3.8 & 156 & 59.2 & 948 & 31 \\
$08|29| 12$ & 18.6 & -54.4 & 4.0 & 165 & 59.2 & 948 & 31 \\
$08|29| 18$ & 18.8 & -55.0 & 3.5 & 161 & 56.6 & 948 & 31 \\
$08|30| 00$ & 18.9 & -55.8 & 3.9 & 172 & 54.0 & 954 & 32 \\
$08|30| 06$ & 19.0 & -56.8 & 4.9 & 174 & 51.4 & 958 & 33 \\
$08|30| 12$ & 19.2 & -58.1 & 6.4 & 171 & 51.4 & 956 & 33 \\
$08|30| 18$ & 19.4 & -59.3 & 5.9 & 170 & 56.6 & 948 & 31 \\
$08|31| 00$ & 19.6 & -60.7 & 6.9 & 171 & 56.6 & 946 & 31 \\
$08|31| 06$ & 19.8 & -62.1 & 6.9 & 171 & 59.2 & 950 & 32 \\
$08|31| 12$ & 20.0 & -63.5 & 6.9 & 171 & 61.7 & 949 & 32 \\
$08|31| 18$ & 20.3 & -65.0 & 7.4 & 168 & 64.3 & 942 \\
\hline
\end{tabular}

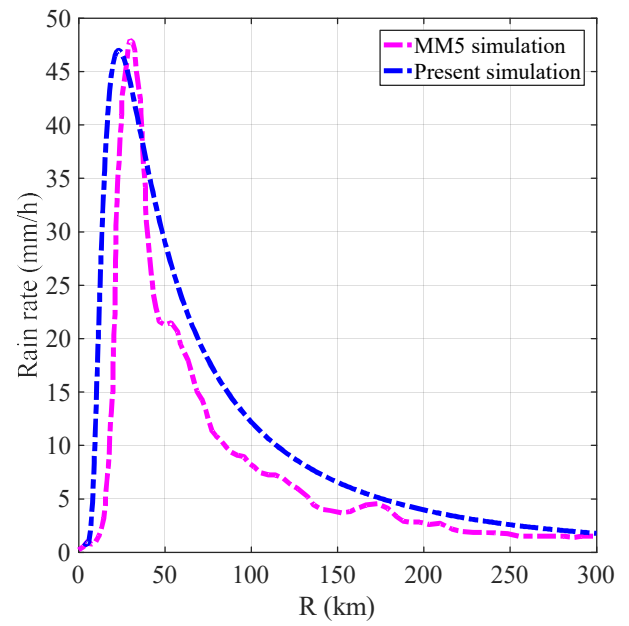

Fig. 3. Comparison of the azimuthally-averaged, rain-rate radial profile of Hurricane Frances 


\subsection{Comparison with PR/TRMM rain fields}

261 To validate the proposed analysis framework for rapid rain rate estimation during tropical 262 cyclones, $38 \mathrm{PR} / \mathrm{TRMM}$ rain frames with a spatial resolution of $5 \mathrm{~km} \times 5 \mathrm{~km}$ were utilized. The 263 parameters of the data collected from the PR/TRMM rain frames are summarized in Table 2 264 (Langousis and Veneziano 2009b). These 38 frames were selected from eight tropical cyclones 265 that cover a wide range of storm intensities. Fig. 4(a) represents a scatterplot of the ratios between 266 the PR/TRMM and simulated rain intensities $i_{P R} / i_{\text {sim }}$. A total number of 73819 points were 267 selected from the 38 TRMM frames, covering a wide range of tropical cyclone spatial locations. 268 All the necessary parameters for the rain rate simulation are taken from Table 2 (Langousis and 269 Veneziano 2009b).

A large dispersion similar to the finding of Langousis and Veneziano (2009a) is observed in

271 Fig. 4(a). It mainly results from the significant small-scale variability of rain rate due to the 272 rainbands and local intensifications. Figure 4(b) depicts the local average and standard deviation 273 of the ratio $i_{P R} / i_{\text {sim }}$ with a moving window of 2000 points. Clearly, the simulation based on the 274 proposed analyses framework of rain field is unbiased since the moving average is close to unity. 275 The moving standard deviation on the other hand is quite large highlighting the significance of the 276 small-scale variability of the tropical cyclone rain field (Powell 1990; Molinari et al. 1994; 277 Langousis and Veneziano 2009a). 
282 Table 2. Tropical cyclones characteristics of the PR/TRMM rain fields (Langousis and Veneziano 2009b)

\begin{tabular}{|c|c|c|c|c|c|c|c|c|}
\hline \multirow[b]{2}{*}{$\begin{array}{l}\text { Hurricane } \\
\text { Name }\end{array}$} & \multicolumn{2}{|c|}{ Hurricane Center } & \multirow[b]{2}{*}{$\begin{array}{l}\text { Storm Speed } \\
(\mathrm{m} / \mathrm{s})\end{array}$} & \multirow[b]{2}{*}{$\begin{array}{c}\text { Storm Direction } \\
(\mathrm{deg})\end{array}$} & \multirow[b]{2}{*}{$\begin{array}{l}V_{\max } \\
(\mathrm{m} / \mathrm{s})\end{array}$} & \multirow[b]{2}{*}{$\begin{array}{l}R_{\max } \\
(\mathrm{km})\end{array}$} & \multirow[b]{2}{*}{$\begin{array}{l}\text { TRMM } \\
\text { Frame }\end{array}$} & \multirow[b]{2}{*}{$\begin{array}{c}\text { Storm } \\
\text { Intensity }\end{array}$} \\
\hline & $\begin{array}{l}\text { Latitude } \\
\text { (deg) }\end{array}$ & $\begin{array}{l}\text { Longitude } \\
\text { (deg) }\end{array}$ & & & & & & \\
\hline \multirow[t]{3}{*}{ Floyd 1999} & 21.7 & -61.6 & 4.9 & 143 & 48.8 & 41 & 10290 & CAT2 \\
\hline & 23.5 & -68.7 & 4.8 & 169 & 64.0 & 37 & 10317 & CAT4 \\
\hline & 23.7 & -70.6 & 5.8 & 171 & 69.3 & 37 & 10321 & CAT4 \\
\hline \multirow[t]{4}{*}{ Lili 2002} & 23.6 & -87.2 & 9.0 & 162 & 51.5 & 20 & 27826 & CAT2 \\
\hline & 24.4 & -88.4 & 6.2 & 141 & 56.5 & 20 & 27830 & CAT2 \\
\hline & 28.4 & -91.4 & 10.1 & 117 & 54.0 & 20 & 27842 & CAT4 \\
\hline & 29.0 & -91.9 & 5.4 & 124 & 41.1 & 20 & 27845 & CAT2 \\
\hline \multirow[t]{6}{*}{ Frances 2004} & 12.6 & -43.7 & 10.9 & 158 & 23.1 & 37 & 38646 & $\mathrm{TS}$ \\
\hline & 15.7 & -49.8 & 5.4 & 139 & 51.4 & 19 & 38667 & CAT3 \\
\hline & 17.0 & -51.3 & 5.3 & 139 & 54.0 & 28 & 38677 & CAT3 \\
\hline & 17.9 & -52.6 & 4.3 & 144 & 59.1 & 28 & 38682 & CAT4 \\
\hline & 19.0 & -57.3 & 4.9 & 180 & 51.4 & 28 & 38708 & CAT3 \\
\hline & 21.2 & -68.5 & 6.1 & 162 & 61.7 & 28 & 38739 & CAT4 \\
\hline \multirow[t]{8}{*}{ Ivan 2004} & 8.9 & -38.9 & 7.6 & 184 & 25.7 & 37 & 38789 & $\mathrm{TS}$ \\
\hline & 10.7 & -50.6 & 12.2 & 185 & 57.5 & 28 & 38814 & CAT4 \\
\hline & 11.2 & -53.4 & 8.1 & 173 & 51.4 & 28 & 38820 & CAT3 \\
\hline & 12.3 & -64.1 & 8.3 & 166 & 61.7 & 19 & 38845 & CAT4 \\
\hline & 12.7 & -66.2 & 7.3 & 164 & 61.7 & 20 & 38851 & CAT4 \\
\hline & 17.4 & -77.3 & 4.1 & 194 & 66.8 & 28 & 38892 & CAT4 \\
\hline & 17.7 & -78.4 & 4.4 & 153 & 64.3 & 28 & 38897 & CAT4 \\
\hline & 25.6 & -87.4 & 5.5 & 112 & 61.7 & 46 & 38954 & CAT4 \\
\hline \multirow[t]{4}{*}{ Jeanne 2004} & 27.4 & -70.6 & 5.5 & 0 & 38.6 & 42 & 39045 & CAT1 \\
\hline & 25.5 & -69.5 & 1.1 & 207 & 41.1 & 37 & 39079 & CAT2 \\
\hline & 26.5 & -74.3 & 7.4 & 173 & 43.7 & 60 & 39106 & CAT2 \\
\hline & 26.5 & -75.6 & 6.5 & 180 & 46.3 & 46 & 39110 & CAT2 \\
\hline \multirow[t]{5}{*}{ Karl 2004} & 11.5 & -35.3 & 7.1 & 176 & 26.7 & 37 & 38987 & $\mathrm{TS}$ \\
\hline & 17.3 & -45.5 & 2.0 & 166 & 57.8 & 32 & 39033 & CAT3 \\
\hline & 19.1 & -47.4 & 5.9 & 121 & 64.0 & 32 & 39048 & CAT4 \\
\hline & 22.9 & -48.6 & 8.2 & 112 & 54.0 & 28 & 39059 & CAT3 \\
\hline & 25.7 & -49.5 & 6.8 & 117 & 48.8 & 28 & 39063 & CAT3 \\
\hline \multirow[t]{3}{*}{ Katrina 2005} & 24.6 & -85.6 & 2.1 & 153 & 51.5 & 56 & 44357 & CAT3 \\
\hline & 25.0 & -86.2 & 3.5 & 146 & 56.5 & 50 & 44361 & CAT3 \\
\hline & 26.9 & -89.0 & 5.5 & 135 & 75.0 & 38 & 44373 & CAT5 \\
\hline \multirow[t]{5}{*}{ Rita 2005} & 24.3 & -85.9 & 5.7 & 189 & 61.7 & 28 & 44743 & CAT4 \\
\hline & 24.9 & -88.0 & 3.9 & 166 & 77.1 & 19 & 44754 & CAT5 \\
\hline & 25.4 & -88.7 & 4.3 & 153 & 72.0 & 19 & 44758 & CAT5 \\
\hline & 26.8 & -91.0 & 5.5 & 135 & 59.1 & 37 & 44770 & CAT4 \\
\hline & 27.4 & -91.9 & 4.8 & 143 & 59.1 & 37 & 44773 & CAT4 \\
\hline
\end{tabular}



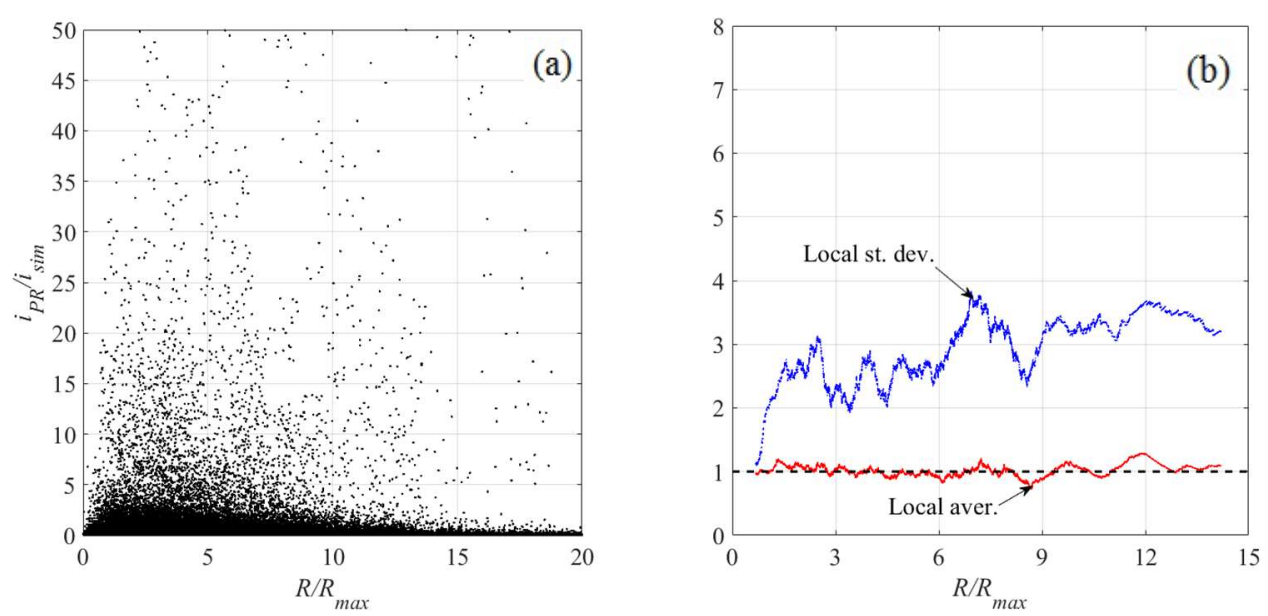

Fig. 4. Comparison of the PR/TRMM and simulated rain rates: (a) Scatter plot of $i_{P R} / i_{\text {sim }}$; (b) Local average and standard deviation of $i_{P R} / i_{\text {sim }}$

\subsection{Comparison with TMI/TRMM and radar observations}

289 The rain distribution of hurricane Dennis (1999) obtained from TMI/TRMM (Lonfat et al. 2004) was compared with the simulation result from the present methodology. As shown in Fig. 5, a good agreement between the simulations and observations is highlighted except in some local intensification regions caused by rainbands. TMI measurements are known to be more accurate

293 for rainfall estimates over ocean than land. On the other hand, the Hydro-Next-Generation Doppler 294 Radar system can measure the rainfall distribution over both ocean and land with very good 295 accuracy (Lin et al. 2010). Hurricane Isabel (2003) was employed here to validate rain field 296 simulation over land based on the present analysis framework. Isabel made landfall in North 297 Carolina on 18 September 2003 as a category 2 tropical cyclone and caused widespread damages 298 from storm surge flooding, wind and riverine flooding (Lin et al. 2010). Figure 6 presents a good 299 agreement between the simulated and observed rainfall distribution up to $200 \mathrm{~km}$ radius. The 300 orographic enhancement of rainfall due to the interaction between the tropical cyclone and the 

model, resulted in large differences beyond the range of $200 \mathrm{~km}$ (Lin et al. 2010).

303

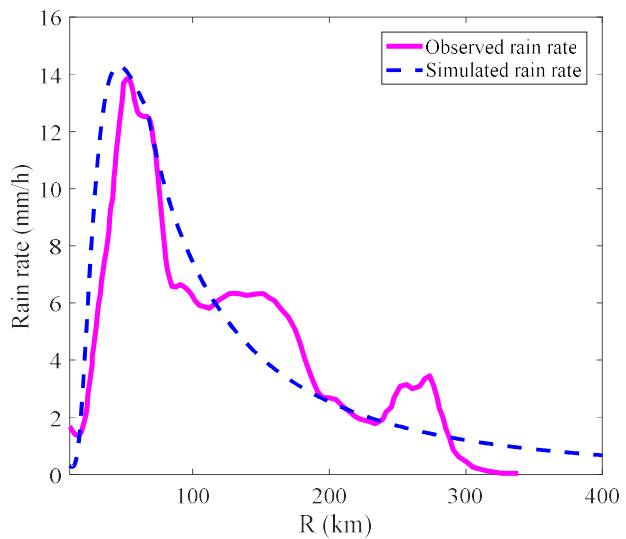

Fig. 5. Comparison of the azimuthally-averaged, rain-rate radial profile of Hurricane Dennis

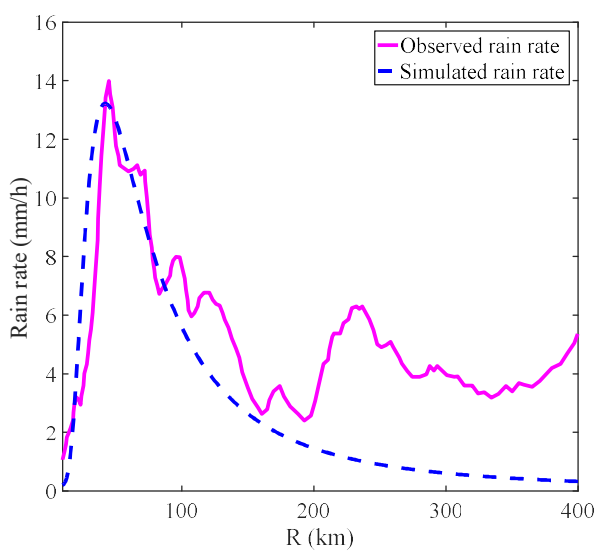

Fig. 6. Comparison of the azimuthally-averaged, rain-rate radial profile of Hurricane Isabel

\section{Rainband simulation}

Tropical cyclones exhibit significant rain rate in the eyewall and a set of rainbands (Willoughby et al. 1984; Willoughby 1988). The complicated underlying mechanisms governing the rainbands make their pattern vary from one tropical cyclone to another (Houze et al. 2006). Hence, it is extremely challenging to systematically simulate these rainbands. The rainbands outside the eyewall are usually characterized by secondary horizontal wind maxima (Samsury and Zipser 
1995). A number of field measurements indicate that the local boundary-layer wind maxima in the rainbands are typically associated with pressure perturbations (e.g., Powell 1990; Yu and Tsai 2010; Lin et al. 2010; Sitkowski et al. 2011; Li and Wang 2012). Since the wind field here is simulated by a large-scale model (Snaiki and Wu 2017a; 2017b) and hence does not account for local intensifications, considerable differences between the simulated and observed rain rates are typically observed in the rainband regions as discussed in the preceding sections.

A good approach to improve the simulation would be based on a proper perturbation of the original wind profile that could characterize the rainbands. The rain rate heavily depends on the wind speed, hence, a perturbation in the wind field will generate a corresponding perturbation in the rain rate and hence the local maxima of the rain intensity (local perturbation scheme). This approach can be more convenient to be implemented by introducing a perturbation in the pressure profile that will generate a corresponding wind perturbation (Holland et al. 2010). To illustrate the adopted scheme, the rain field of hurricane Dennis (Fig. 5) was revisited to incorporate the contribution of the rainbands. The rainband locations were first identified from the TMI imagery [Fig. 7(b)]. Then, the simulated wind speeds at a 10-meter height were compared with those from the Remote Sensing System QuikScat (version-4) data [Fig. 7(a)] (Ricciardulli and Wentz, 2015) to obtain the perturbation values. Table 3 compares and presents the observed and simulated wind speeds in three different rainband regions. The consideration of perturbations in the wind field leads to an improved rain rate, as shown in Fig. 8. A good agreement between the observed and simulated profiles is observed. Figure 9 presents a comparison of the simulated rain rates of Hurricane Dennis with and without considerations of the rainbands. The corresponding correlation coefficients between the observations and simulations are 0.96 and 0.92 , respectively. While the results demonstrate that the rain intensities predicted by both approaches match reasonably well 
337 with the measured data, the simulation accuracy is certainly improved by integrating the rainband effects.

(a)

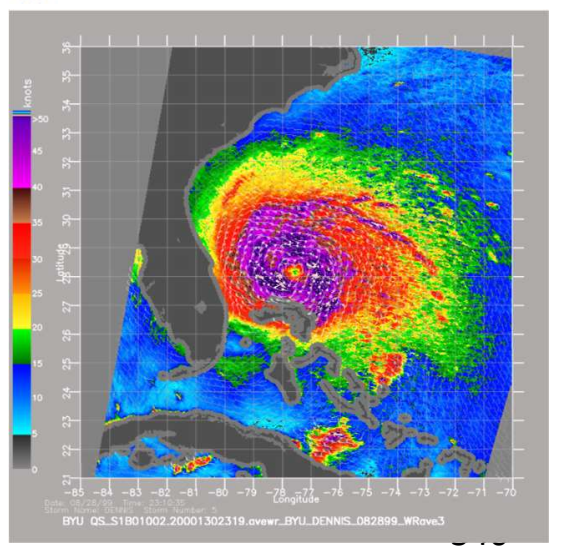

(b)

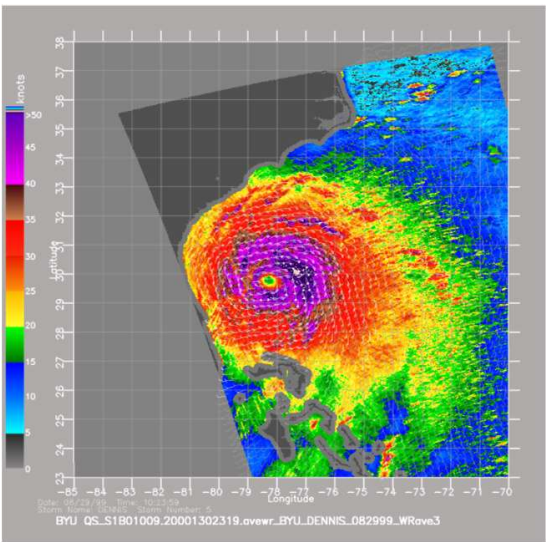

50w $7 \mathrm{w}^{\circ} \mathrm{W}$
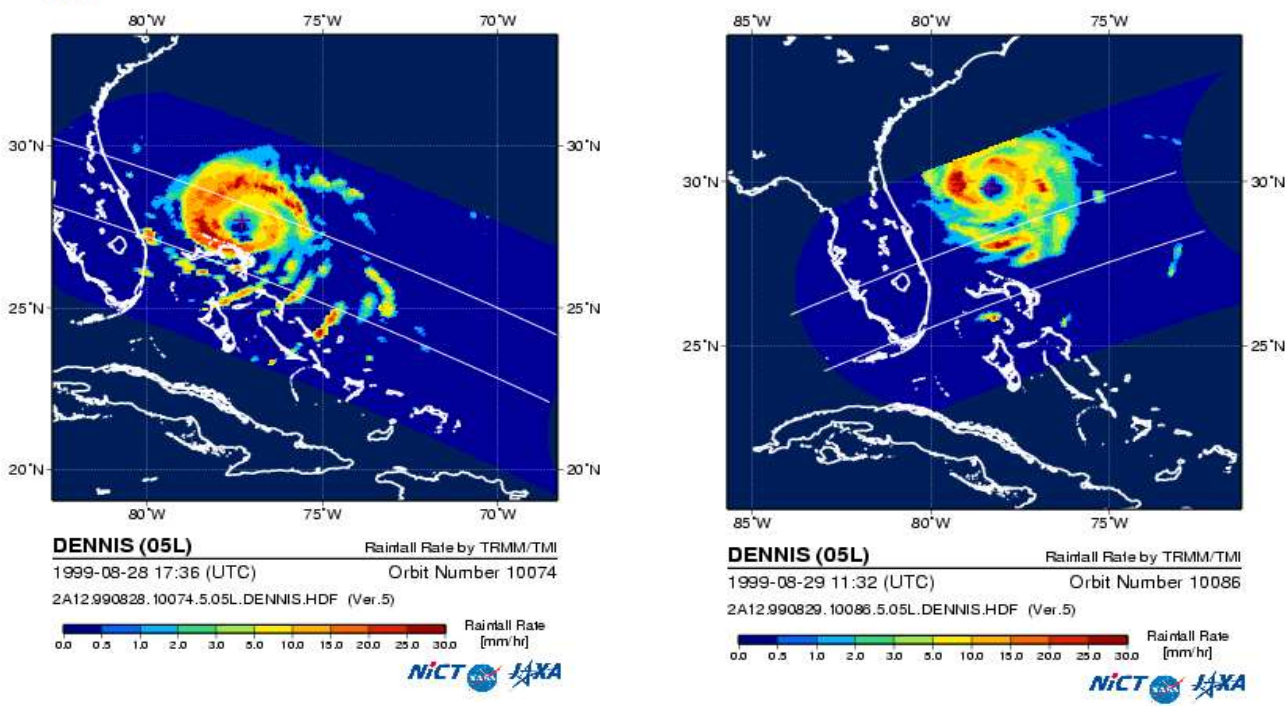

Fig. 7. Hurricane Dennis (1999) wind and rain fields: (a) Surface wind speed distribution obtained from QuikScat on August 28 (left) and August 29 (right); (b) Surface rain rate provided by TMI/TRMM on August 28 (left) and August 29 (right) 
354 Table 3. Comparison between the observed (QuikScat) and simulated surface wind speed of Hurricane Dennis in the 355 rainband regions

\begin{tabular}{cccc}
\hline$r(\mathrm{~km})$ & $\theta(\mathrm{deg})$ & $U_{\text {QuikScat }}(\mathrm{m} / \mathrm{s})$ & $U_{\text {simulated }}(\mathrm{m} / \mathrm{s})$ \\
\hline 133 & 90 & 25.70 & 22.20 \\
137 & 60 & 25.00 & 22.25 \\
236 & 194 & 16.00 & 12.00 \\
\hline
\end{tabular}

356

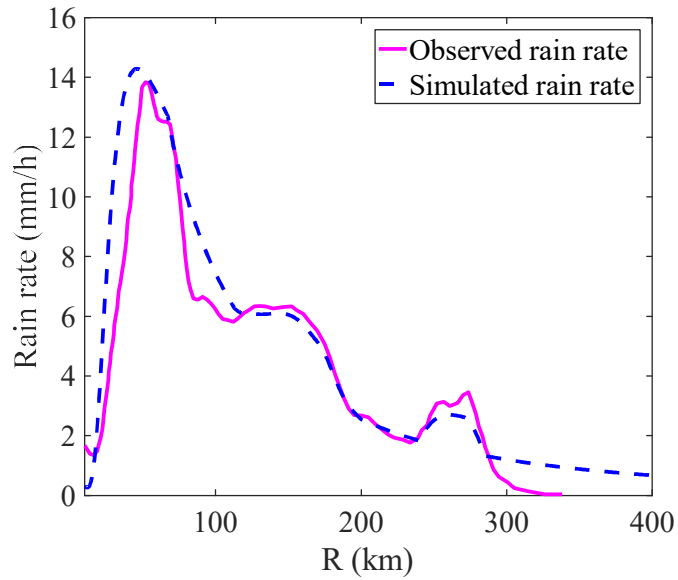

Fig. 8. Comparison of the improved, azimuthally-averaged, rain-rate radial profile of Hurricane Dennis

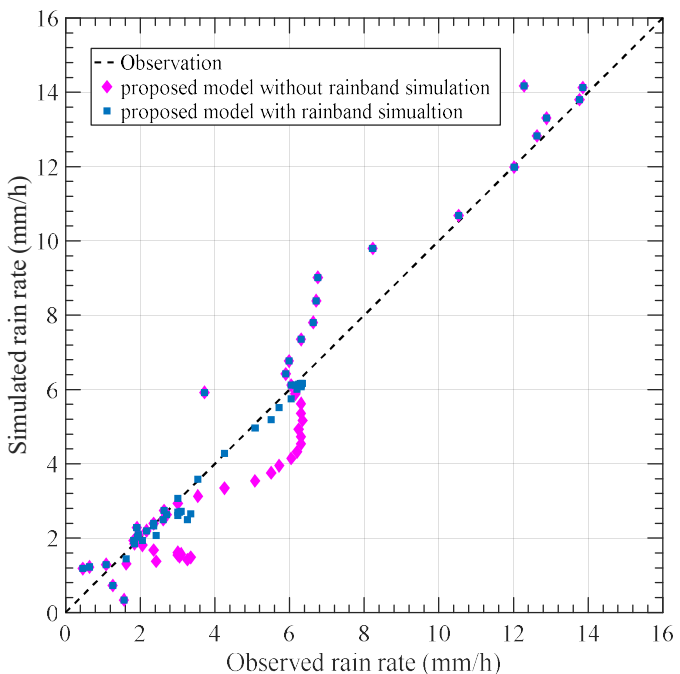

Fig. 9. Comparison of the azimuthally-averaged rain rates of Hurricane Dennis 


\section{Sensitivity analysis}

Numerous studies have demonstrated based on field measurements and numerical simulations that the rainfall distribution varies with a number of environmental factors (e.g., roughness) and inherent tropical cyclone features (e.g., intensity and translation speed) (Lonfat et al, 2004). The present rain rate analysis framework explicitly depends on these parameters. Figure 10 illustrates the sensitivity of the rain intensity to several selected parameters, namely $B$ Holland parameter, $r_{m}$ radius of maximum wind, $c$ translation speed, $\Delta p$ central pressure difference, $k_{m}$ turbulent diffusivity, and $z_{0}$ equivalent roughness length. The base case scenario is taken as: $B=1$, $r_{m}=30 \mathrm{~km}, c=10 \mathrm{~m} / \mathrm{s}, \Delta p=70 \mathrm{hpa}, k_{m}=50 \mathrm{~m}^{2} / \mathrm{s}$, and $z_{0}=0.001 \mathrm{~m}$. The radial profile of the rain rate was taken at $\theta=0^{\circ}$ (counterclockwise positive from the East) for all simulations.

As indicated in Fig. 10, the central pressure difference $\Delta p$, translational tropical cyclone speed $c$ and surface roughness $z_{0}$ have significant effects on the rain rate. Actually, it has been widely reported that the surface roughness can substantially alter the rain intensity (e.g., Trenberth et al. 2007; Langousis and Veneziano 2009a; and Lin et al. 2010). Also, a higher value of $\Delta p$, corresponding to a larger maximum wind $v_{m}$ (Holland et al. 2010), leads to more intense rain. This result agrees with the observations and findings of the literature (e.g., Lonfat et al. 2004; Tuleya et al. 2007; Langousis and Veneziano 2009a). Similarly, an increase of the translational tropical cyclone speed results in the enhancement of the total precipitation. Figure 10 also implies that the smaller radius of maximum wind is associated with a more peaked profile shifted to the tropical cyclone center. The Holland's parameter $B$ mainly modifies the decay rate of the rainfall intensity profile and presents small effects on the maximum rain rate. In addition, low sensitivity of the rain rate to the vertical turbulent diffusivity is noted in the figure. 

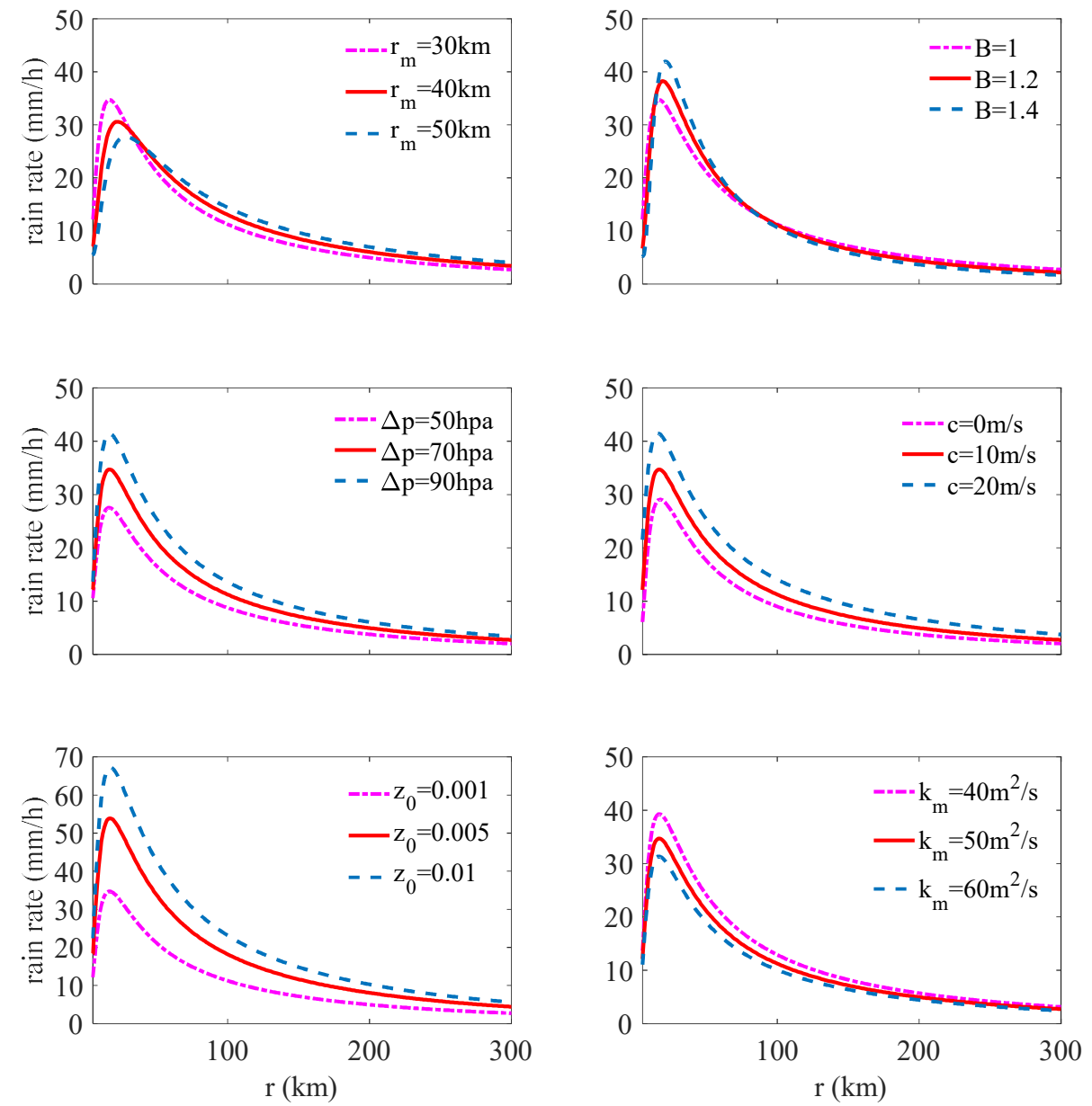

Fig. 10. Sensitivity analysis of the rain rate at $\theta=0^{\circ}$ study parameters: $B=1.2 ; c=3 \mathrm{~m} / \mathrm{s} ; r_{m}=40 \mathrm{~km} ; \Delta p=60 \mathrm{hpa} ; z_{0}=0.01 \mathrm{~m}$. Figures $11(\mathrm{a})$ and

391 11(b) depict the three-dimensional shaded surface of the rain intensity and their corresponding 392 contours, respectively. Due mainly to the tropical cyclone motion, the rain field is asymmetric. 393 This result conforms with the finding of Langousis and Veneziano (2009a), highlighting the 394 maximum rain rate location near the radius of maximum winds in the eyewall region (Lonfat et al. 395 2004; Tuleya et al. 2007). 
(a)

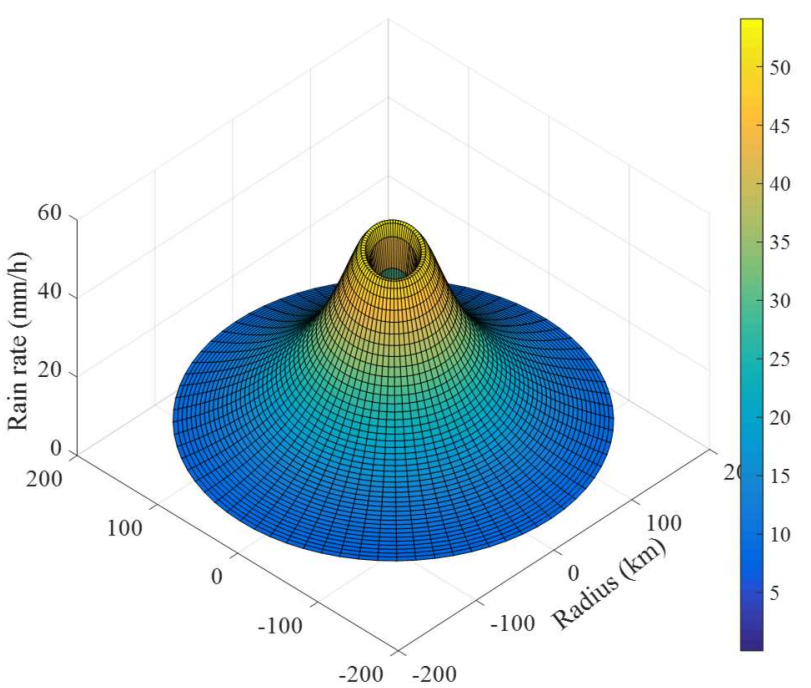

(b)

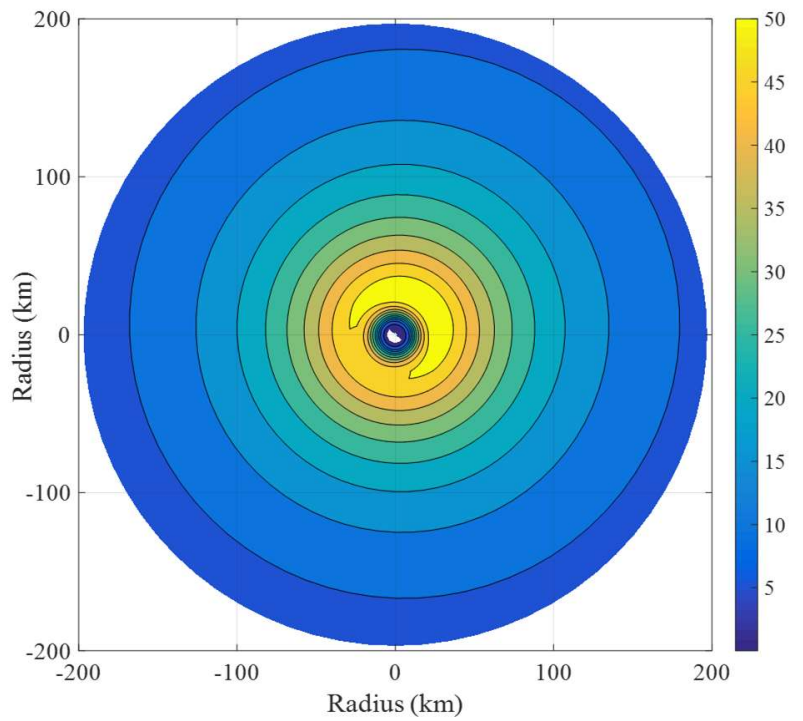

397 tropical cyclone wind field simulation, namely storm location, approach angle, translation speed,

412 radius of maximum wind, pressure profile, surface drag coefficient, and turbulent diffusivity. The
Fig. 11. Spatial distribution of the rain rate: (a) Three-dimensional shaded surface of the rain intensity; (b) Contours of the rain rate

\section{Concluding remarks}

A new, analytical framework for rapid rain rate estimation was proposed in this study. The rain rate formula was essentially developed based on the observation that rain-induced momentum flux at the surface cannot be ignored. The total surface stress results mainly from momentum flux contributions of wind and rain. The obtained results indicate that the spatial distribution of the rainfall field is governed by the wind field inside the tropical cyclone. This observation confirms the findings of several previous studies in which the rain intensity is shown to be highly correlated with the horizontal wind speed. A recently developed, height-resolving wind field model was utilized during the model construction leading to a linear, analytical solution of the surface rain rate. The obtained analysis framework for rain field explicitly depends on parameters for a typical 
413 sensitivity analysis was extensively carried out to investigate the effects of several tropical cyclone

414 and environmental parameters on the rain rate. It has been demonstrated that the rain rate heavily

415 depends on the central pressure difference, translational tropical cyclone speed and surface

416 roughness. The proposed analysis framework for the rain field is based on the large-scale

417 horizontal wind field, therefore, it does not account for local rainfall intensifications due to

418 rainbands. A plausible approach based on the local perturbation scheme was introduced to simulate

419 the rain rates inside the rainband regions. The present analytical framework for rapid estimate of

420 rain rate offers good simulation results that are consistent with tropical cyclone observations. It

421 can be readily used in conjunction with the Monte Carlo techniques for risk analysis of tropical

422 cyclone hazards.

423

424 Acknowledgments

425 The support for this project provided by the NSF Grant \# CMMI 15-37431 is gratefully 426 acknowledged. 


\section{Appendix A}

430 The drag force $f_{i}$ exerted by one raindrop on air in the horizontal direction is introduced:

$431 \quad \boldsymbol{f}_{i}=\frac{1}{2} \rho_{a} C_{d, r} V_{\text {rel }}\left(\boldsymbol{V}_{\text {rain }}-\boldsymbol{V}_{\text {wind }}\right) \pi r_{d}^{2}$

432 where $C_{d, r}=$ drag coefficient for a raindrop of radius $r_{d} ; \boldsymbol{V}_{\text {rain }}=$ raindrop horizontal velocity; $\boldsymbol{V}_{\text {wind }}$

$433=$ wind velocity in the horizontal direction; and $V_{r e l}=$ the total relative speed of the raindrop. As a

434 result, the total drag force $f_{d}$ applied on a tiny volume of air $V=A \Delta z$ can be obtained as follows:

$435 \quad f_{d}=\frac{3 R \rho_{a} C_{d, r} V\left(\boldsymbol{V}_{\text {rain }}-\boldsymbol{V}_{\text {wind }}\right)}{4 d}$

436 where $d=$ the raindrop diameter. The total drag force is then integrated into the governing equation

437 of the wind velocity [Eq. (18)]. With several mathematical manipulations, one can obtain the

438 gradient wind speed as follows (Snaiki and Wu 2017c):

439

$v_{\theta g}=\frac{-\left(f+\frac{A^{2}}{\xi_{a g}}\right)+\frac{c \sin (v-\theta)}{r}\left(1+\frac{A^{2}}{\xi_{a g}^{2}}\right)}{\frac{2}{r}\left(1+\frac{A^{2}}{\xi_{a g}^{2}}\right)}+$

$$
\frac{\left[\left(f+\frac{A^{2}}{\xi_{a g}}-\frac{c \sin (v-\theta)}{r}\left(1+\frac{A^{2}}{\xi_{a g}^{2}}\right)\right)^{2}+\frac{4}{\rho_{a} r} \frac{\partial p}{\partial r}\left(1+\frac{A^{2}}{\xi_{a g}^{2}}\right)\right]^{1 / 2}}{\frac{2}{r}\left(1+\frac{A^{2}}{\xi_{a g}^{2}}\right)}
$$

440 where $A=\frac{\pi C_{d, r} N r_{d}{ }^{2}}{2} \gamma_{1}$; and $N=\frac{3 R}{4 \pi r_{d}^{3}}$ is the number of raindrops per second on a unit area. On

441 the other hand, the frictional wind speed components can be obtained as follows (Snaiki and Wu $442 \quad 2017 c):$ 
$443 \quad v_{r}^{\prime}=Y e^{-a z^{\prime}}\left[W_{1} \cos \left(b z^{\prime}\right)+W_{2} \sin \left(b z^{\prime}\right)\right]$

$444 \quad v_{\theta}^{\prime}=e^{-a z^{\prime}}\left[W_{2} \cos \left(b z^{\prime}\right)-W_{1} \sin \left(b z^{\prime}\right)\right]$

445 where $Y=\sqrt{p / q} ; p=\frac{1}{2 k_{m}} \xi_{g} ; q=\frac{1}{2 k_{m}} \xi_{a g} ; A^{\prime}=\frac{N C_{d, r} \pi r_{d}{ }^{2}}{2} \gamma_{2}$. The variables $a$ and $b$ are defined 446 as:

$447 \quad a=\sqrt{\frac{A^{\prime} / k_{m}+\sqrt{A^{\prime 2} / k_{m}{ }^{2}+4 p q}}{2}}$

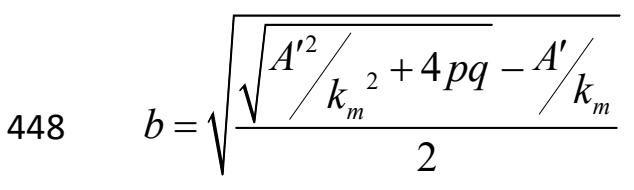

449 The variables $W_{1}$ and $W_{2}$ are determined form the boundary conditions and presented as follows:

$450 \quad W_{1}=-\frac{(a / b+\chi-Z)(\chi / Y-Z / Y) v_{r g}+(\chi-Z) v_{\theta g}}{1+\left(\frac{a}{b}+\chi-Z\right)^{2}}$

$451 \quad W_{2}=\frac{(\chi / Y-Z / Y) v_{r g}-(a / b+\chi-Z)(\chi-Z) v_{\theta g}}{1+(a / b+\chi-Z)^{2}}$

452 where $\chi=\frac{C_{d, a}\left|v_{s}\right|}{k b} ; Z=\frac{\gamma_{r} \rho_{r} R}{\rho_{a} b k} ;$ and $v_{s}=$ total wind velocity near the ground surface. 
455 used for the observed wind data at approximately $10 \mathrm{~m}$ height. As shown in Fig. 12, the results 456 generated by the present model are consistent with hurricane Katrina wind field observations.
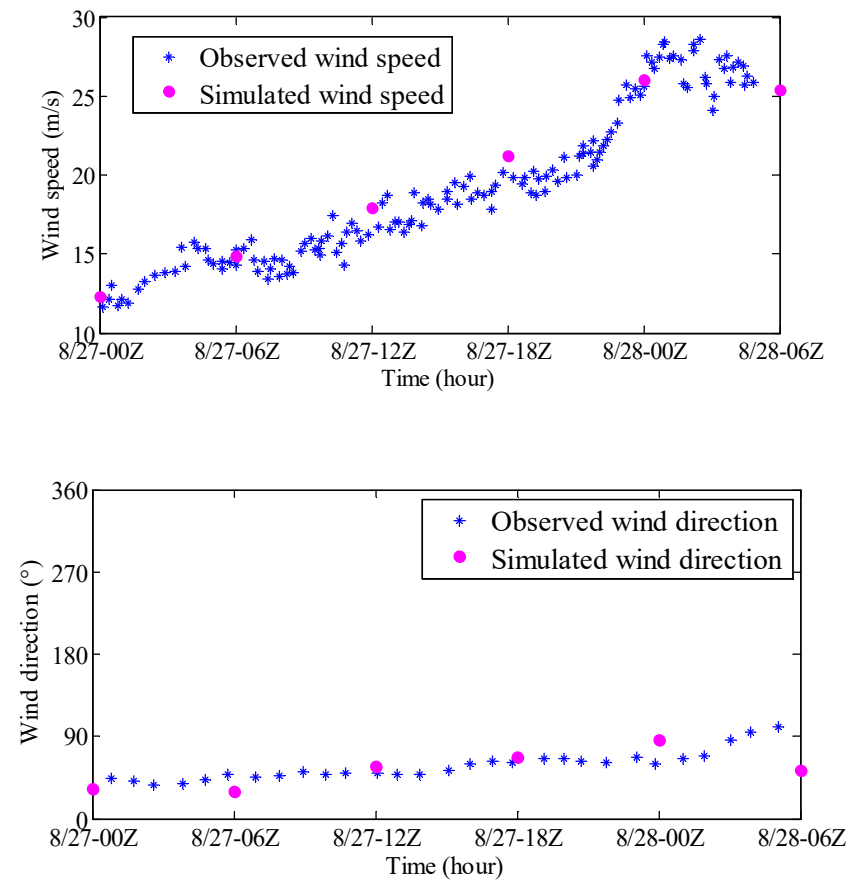

Fig. 10. Observed and simulated wind speeds (top) and directions (bottom) of Hurricane Katrina 460 


\section{References}

Andreas, E.L., 2004. Spray stress revisited. Journal of Physical Oceanography, 34(6), pp.1429-1440.

Bryant, K.M. and Akbar, M., 2016. An Exploration of Wind Stress Calculation Techniques in Hurricane Storm Surge Modeling. Journal of Marine Science and Engineering, 4(3), 58.

Bell, M.M., Montgomery, M.T. and Emanuel, K.A., 2012. Air-sea enthalpy and momentum exchange at major hurricane wind speeds observed during CBLAST. Journal of the Atmospheric Sciences, 69(11), pp.3197-3222.

Caldwell, D.R. and Elliott, W.P., 1971. Surface stresses produced by rainfall. Journal of Physical Oceanography, 1(2), pp.145-148.

Caldwell, D.R. and Elliott, W.P., 1972. The effect of rainfall on the wind in the surface layer. Boundary-Layer Meteorology, 3(2), pp.146-151.

Chen, S.S., Zhao, W., Donelan, M.A., Price, J.F. and Walsh, E.J., 2007. The CBLAST-Hurricane program and the next-generation fully coupled atmosphere-wave-ocean models for hurricane research and prediction. Bulletin of the American Meteorological Society, 88(3), pp.311-317.

Chen, S.S., Zhao, W., Donelan, M.A. and Tolman, H.L., 2013. Directional wind-wave coupling in fully coupled atmosphere-wave-ocean models: Results from CBLAST-Hurricane. Journal of the Atmospheric Sciences, 70(10), pp.3198-3215.

Clayson, C.A. and Kantha, L.H., 1999. Turbulent kinetic energy and its dissipation rate in the equatorial mixed layer. Journal of physical oceanography, 29(9), pp.2146-2166.

Donelan, M.A., Haus, B.K., Reul, N., Plant, W.J., Stiassnie, M., Graber, H.C., Brown, O.B. and Saltzman, E.S., 2004. On the limiting aerodynamic roughness of the ocean in very strong winds. Geophysical Research Letters, 31(18), L18306.

Emanuel, K.A., 1995. Sensitivity of tropical cyclones to surface exchange coefficients and a revised steady-state model incorporating eye dynamics. Journal of the Atmospheric Sciences, 52(22), pp.3969-3976.

Fairall, C.W., Kepert, J.D. and Holland, G.J., 1994. The effect of sea spray on surface energy transports over the ocean. Global Atmos. Ocean Syst, 2(2-3), pp.121-142.

Fairall, C.W., Bradley, E.F., Rogers, D.P., Edson, J.B. and Young, G.S., 1996. Bulk parameterization of air-sea fluxes for tropical ocean-global atmosphere coupled-ocean atmosphere response experiment. Journal of Geophysical Research: Oceans, 101(C2), pp.3747-3764.

Fu, X., Li, H.N. and Yi, T.H., 2015. Research on motion of wind-driven rain and rain load acting on transmission tower. Journal of Wind Engineering and Industrial Aerodynamics, 139, pp.27-36.

Garratt, J.R., 1977. Review of drag coefficients over oceans and continents. Monthly weather review, 105(7), pp.915929.

Georgiou, P.N., 1986. Design Wind Speeds in Tropical Cyclone-prone Regions. PhD Thesis University of Western Ontario, London, Ontario, Canada.

Groisman, P.Y., Karl, T.R., Easterling, D.R., Knight, R.W., Jamason, P.F., Hennessy, K.J., Suppiah, R., Page, C.M., Wibig, J., Fortuniak, K. and Razuvaev, V.N., 1999. Changes in the probability of heavy precipitation: important indicators of climatic change. In Weather and Climate Extremes (pp. 243-283). Springer Netherlands.

Guo, J.C., Urbonas, B. and Stewart, K., 2001. Rain catch under wind and vegetal cover effects. Journal of Hydrologic Engineering, 6(1), pp.29-33. 
Holland, G.J., Belanger, J.I. and Fritz, A., 2010. A revised model for radial profiles of hurricane winds. Monthly Weather Review, 138(12), pp.4393-4401.

Holthuijsen, L.H., Powell, M.D. and Pietrzak, J.D., 2012. Wind and waves in extreme hurricanes. Journal of Geophysical Research: Oceans, 117, C09003.

Houk, D. and Green, T., 1976. A note on surface waves due to rain. Journal of Geophysical Research, 81(24), pp.44824484 .

Houze Jr, R.A., Cetrone, J., Brodzik, S.R., Chen, S.S., Zhao, W., Lee, W.C., Moore, J.A., Stossmeister, G.J., Bell, M.M. and Rogers, R.F., 2006. The hurricane rainband and intensity change experiment: Observations and modeling of Hurricanes Katrina, Ophelia, and Rita. Bulletin of the American Meteorological Society, 87(11), pp.1503-1521.

Huang, C.H., 2012. Modification of the Charnock wind stress formula to include the effects of free convection and swell. In Advanced Methods for Practical Applications in Fluid Mechanics. InTech, pp.47-71.

Huffman, G.J., Adler, R.F., Bolvin, D.T. and Nelkin, E.J., 2010. The TRMM multi-satellite precipitation analysis (TMPA). In Satellite rainfall applications for surface hydrology (pp. 3-22). Springer Netherlands.

Jarosz, E., Mitchell, D.A., Wang, D.W. and Teague, W.J., 2007. Bottom-up determination of air-sea momentum exchange under a major tropical cyclone. Science, 315(5819), pp.1707-1709.

Kaplan, J. and DeMaria, M., 1995. A simple empirical model for predicting the decay of tropical cyclone winds after landfall. Journal of applied meteorology, 34(11), pp.2499-2512.

Kumar, R.R., Kumar, B.P. and Subrahamanyam, D.B., 2009. Parameterization of rain induced surface roughness and its validation study using a third generation wave model. Ocean Science Journal, 44(3), pp.125-143.

Kummerow, C., Barnes, W., Kozu, T., Shiue, J. and Simpson, J., 1998. The tropical rainfall measuring mission (TRMM) sensor package. Journal of atmospheric and oceanic technology, 15(3), pp.809-817.

Landsea, C.W., 2000. Climate variability of tropical cyclones: past, present and future. Storms. Routledge, New York, pp. 220-241.

Langousis, A. and Veneziano, D., 2009a. Theoretical model of rainfall in tropical cyclones for the assessment of longterm risk. Journal of Geophysical Research: Atmospheres, 114, D02106.

Langousis, A. and Veneziano, D., 2009b. Long-term rainfall risk from tropical cyclones in coastal areas. Water resources research, $45, \mathrm{~W} 11430$.

Li, Q. and Wang, Y., 2012. Formation and quasi-periodic behavior of outer spiral rainbands in a numerically simulated tropical cyclone. Journal of the Atmospheric Sciences, 69(3), pp.997-1020.

Lin, N., Smith, J.A., Villarini, G., Marchok, T.P. and Baeck, M.L., 2010. Modeling extreme rainfall, winds, and surge from Hurricane Isabel (2003). Weather and Forecasting, 25(5), pp.1342-1361.

Lonfat, M., Marks Jr, F.D. and Chen, S.S., 2004. Precipitation distribution in tropical cyclones using the Tropical Rainfall Measuring Mission (TRMM) microwave imager: A global perspective. Monthly Weather Review, 132(7), pp.1645-1660.

Lonfat, M., Rogers, R., Marchok, T. and Marks Jr, F.D., 2007. A parametric model for predicting hurricane rainfall. Monthly Weather Review, 135(9), pp.3086-3097.

Meng, Y., Matsui, M. and Hibi, K., 1995. An analytical model for simulation of the wind field in a typhoon boundary layer. Journal of Wind Engineering and Industrial Aerodynamics, 56(2-3), pp.291-310. 
Molinari, J., Moore, P.K., Idone, V.P., Henderson, R.W. and Saljoughy, A.B., 1994. Cloud-to-ground lightning in Hurricane Andrew. Journal of Geophysical Research: Atmospheres, 99(D8), pp.16665-16676.

Powell, M.D., 1990. Boundary layer structure and dynamics in outer hurricane rainbands. Part I: Mesoscale rainfall and kinematic structure. Monthly Weather Review, 118(4), pp.891-917.

Powell, M.D., Vickery, P.J. and Reinhold, T.A., 2003. Reduced drag coefficient for high wind speeds in tropical cyclones. Nature, 422(6929), pp.279-283.

Rappaport, E.N., 2000. Loss of life in the United States associated with recent Atlantic tropical cyclones. Bulletin of the American Meteorological Society, 81(9), pp.2065-2073.

Ricciardulli, L. and Wentz, F.J., 2015. A scatterometer geophysical model function for climate-quality winds: QuikSCAT Ku-2011. Journal of Atmospheric and Oceanic Technology, 32(10), pp.1829-1846.

Samsury, C.E. and Zipser, E.J., 1995. Secondary wind maxima in hurricanes: Airflow and relationship to rainbands. Monthly weather review, 123(12), pp.3502-3517.

Shu, Z.R., Li, Q.S., He, Y.C. and Chan, P.W., 2017. Vertical wind profiles for typhoon, monsoon and thunderstorm winds. Journal of Wind Engineering and Industrial Aerodynamics, 168, pp.190-199.

Sitkowski, M., Kossin, J.P. and Rozoff, C.M., 2011. Intensity and structure changes during hurricane eyewall replacement cycles. Monthly Weather Review, 139(12), pp.3829-3847.

Smith, R.K., 1968. The surface boundary layer of a hurricane. Tellus, 20(3), pp.473-484.

Snaiki, R. and Wu, T., 2017a. Modeling tropical cyclone boundary layer: Height-resolving pressure and wind fields. Journal of Wind Engineering and Industrial Aerodynamics, 170, pp.18-27.

Snaiki, R. and Wu, T., 2017b. A linear height-resolving wind field model for tropical cyclone boundary layer. Journal of Wind Engineering and Industrial Aerodynamics, 171, pp.248-260.

Snaiki, R. and Wu, T., 2017c. Dynamic Interaction of Wind and Rain Fields in the Boundary Layer of a Tropical Cyclone. Proceedings of Engineering Mechanics Institute Conference 2017 (EMI 2017), May, 2017, San Diego, CA, USA.

Taylor, G.I., 1916. Skin friction of the wind on the earth's surface. Proceedings of the Royal Society of London. Series A, Containing Papers of a Mathematical and Physical Character, 92(637), pp.196-199.

Trenberth, K.E., Davis, C.A. and Fasullo, J., 2007. Water and energy budgets of hurricanes: Case studies of Ivan and Katrina. Journal of Geophysical Research: Atmospheres, 112(D23106).

Tse, K.T., Li, S.W., Chan, P.W., Mok, H.Y. and Weerasuriya, A.U., 2013. Wind profile observations in tropical cyclone events using wind-profilers and doppler SODARs. Journal of Wind Engineering and Industrial Aerodynamics, 115, pp.93-103.

Tuleya, R.E., DeMaria, M. and Kuligowski, R.J., 2007. Evaluation of GFDL and simple statistical model rainfall forecasts for US landfalling tropical storms. Weather and forecasting, 22(1), pp.56-70.

Vickery, P.J., Wadhera, D., Powell, M.D. and Chen, Y., 2009. A hurricane boundary layer and wind field model for use in engineering applications. Journal of Applied Meteorology and Climatology, 48(2), pp.381-405.

Willoughby, H.E., Marks Jr, F.D. and Feinberg, R.J., 1984. Stationary and moving convective bands in hurricanes. Journal of the Atmospheric Sciences, 41(22), pp.3189-3211.

Willoughby, H.E., 1988. The dynamics of the tropical cyclone core. Australian Meteorological Magazine, 36, pp.183191. 
579 Wilson, P.S. and Toumi, R., 2005. A fundamental probability distribution for heavy rainfall. Geophysical Research $580 \quad$ Letters, 32, L14812.

581 Wong, B. and Toumi, R., 2016. Effect of extreme ocean precipitation on sea surface elevation and storm 582 surges. Quarterly Journal of the Royal Meteorological Society, 142(699), pp.2541-2550.

583 Woolhiser, D.A. and Roldan, J., 1982. Stochastic daily precipitation models: 2. A comparison of distributions of 584 amounts. Water resources research, 18(5), pp.1461-1468.

585 Wu, J., 1973. Spray in the atmospheric surface layer: Laboratory study. Journal of Geophysical Research, 78(3), $586 \quad$ pp.511-519.

587 Yu, C.K. and Tsai, C.L., 2010. Surface pressure features of landfalling typhoon rainbands and their possible 588 causes. Journal of the Atmospheric Sciences, 67(9), pp.2893-2911.

589 Zhao, D., Ma, X., Liu, B. and Xie, L., 2013. Rainfall effect on wind waves and the turbulence beneath air-sea interface. 590 Acta Oceanologica Sinica, 32(11), pp.10-20. 